\title{
Ruthenium (III) Catalysed Oxidation of Guanidine hydrochloride by Periodate in aqueous alkaline medium
}

\author{
Abdulrazak Shekhasaheb Bagawan \\ Associate Professor, Department of Chemistry, M.G.V.C. Arts, Commerce and Science College, \\ Muddebihal, Dt: Vijayapur St: Karnataka India-586212
}

\begin{abstract}
The activity of periodate as an oxidising agent varies greatly as a function of $\mathrm{pH}$ and is capable subtle control. In acid, it is one of the most powerful oxidising agents known, qualitatively and rapidly converting manganese (II) salts to periodate, while in alkaline solution, it is slightly less oxidising than hypochlorite. In alkaline medium, periodate exists as different species involving multiple equilibria ${ }^{[1,2]}$ and it needs to know the active form of oxidant in the reaction. However, there are numerous reports ${ }^{[3]}$ on the oxidation of organic compounds.

Guanidine hydrochloride $(\mathrm{GH})$ finds its applications in analytical chemistry, oxidation of guanidine pharmaceuticals and polymer industries. Oxidation of guanidine hydrochloride by permanganate ${ }^{[4]}$ and osmium (VIII) ${ }^{[5]}$ catalysed has been carried out earlier in our laboratory. In continuation of oxidation of guanidine hydrochloride, we have chosen this title reaction for kinetic study. The literature survey reveals that there are no reports on mechanistic studies of oxidation of guanidine hydrochloride by alkaline periodate Thus in order to explore the mechanism of oxidation and to know the active species of periodate in strongly alkaline medium the detail kinetic study of the title reaction is undertaken.

Ruthenium (III) acts as an efficient catalyst ${ }^{[7]}$ in several redox reactions and use of $\mathrm{RuCl}$, as a homogenous catalyst in both acid and alkaline media is of interest. Though the mechanism of catalysis depends on the nature of substrate, oxidant, and other experimental conditions, it has been shown that metal ions acts as catalyst by one of these different paths like formation of a complex with reactants or free radicals, etc. The Ruthenium (III) catalysis of a number of organic and inorganic reactions in alkaline media have been studied ${ }^{[8]}$. The mechanism of the catalysis can be quite complicated due to the formulation of different intermediate complexes, free radicals and different oxidation states of rutheniumn. The uncatalysed reaction has been studied earlier by the same authors ${ }^{[7]}$, now the catalysed reaction is undertaken to know the changes and to shape out the comparative study between catalysed and uncatalysed reaction. A microscopic amount of osmium (VIII) is sufficient to catalyse there action in alkaline medium and a variety of mechanism are possible. The literature survey reveals that there are no reports on mechanistic studies of osmium (VIII) catalysed oxidation of guanidine hydrochloride by alkaline periodate. Thus in order to explore the mechanism of oxidation and to know the active species of osmium (VII) in strongly alkaline medium the detail kinetic study of the title reaction is undertaken.
\end{abstract}

Key words: Kinetics, Oxidation, Ruthenium (III), Guanidine, Periodate, alkaline medium.

\section{INTRODUCTION}

Kinetic studies and stereo-chemical studies provide the most powerful methods of investigating detailed reaction mechanism. Although most chemical reactions are extremely complex and the rate equations are often baffling in interpretation, there is a growing realisation that the complexity is due mainly to the presence of many simple or bimolecular steps which are going on successively or simultaneously or in opposition to each other. The great hope for advances in chemical kinetics lies in the fact that these simple unimolecular or bimolecular steps can be understood and calculated. The challenge is to put various steps together to give the overall reaction and predict its rate.

The experimental part of the subject deals with ways of measuring precisely the rates of reactions at various varying conditions of experiments. The interpretation of results leads to an understanding of the mechanism of the reaction. The combination of the results of a large number of experiments gives rise to general theories of chemical reactivity, The important steps in any kinetic investigations are; (1) collection of kinetic data (2) establishment of relationships between the rate and reaction mixture composition (3) study of structural effects and (4) interpretation of the collected data to arrive at reaction mechanism.

The study of reaction kinetics gives wealth of information about the nature and course of reactions. The order of a reaction can be used to interpret the reaction on molecular level. For example, the chemists by considering the order of 


\section{DOI: 10.17148/IARJSET.2021.81208}

a reaction with respect to different reactive species, predict the sequence in which bonds break and atoms rearrange during the reaction and hence propose reaction mechanism.

The kinetic data will be the source of a great deal of detailed insight into the mechanism of a reaction. Although, other types of experimental evidences are also sought for purpose of formulating a reaction mechanism, the study of reaction kinetics generally forms the backbone of a thorough mechanistic investigation. One of the most intriguing areas of chemistry is that which deals with the mechanism of a reaction. The mechanism is a mental model advisor to explain the facts. To many chemists the real heart of chemistry is the study of the mechanisms. Reaction rate is of great practical interest in both laboratory and industrial practice. It is clearly necessary to understand the factors controlling the rate at least to some extent before a reaction becomes useful on almost any scale. One important outcome of mechanistic studies has been the chemistry of unstable intermediates, of compounds that are normally not isolable.

Finally, as an area of pure science in itself, the study of rates and mechanism is one of rich varieties, concerned with chemistry of every element and full of experimental challenge. Thus, chemical kinetics can be defined as branch of physical chemistry devoted to the laws of chemical reactions in time. Hence kinetic studies are receiving much importance in recent years.

Electron transfer is only one of the many pathways by which a redox reaction can occur. Nonetheless, the importance of electron transfer in transition metal redox chemistry has been recognized ${ }^{[9]}$ and more recently it has become increasingly obvious that many reactions in organic chemistry Once thought to be concerted in nature also occur via sequential one electron steps ${ }^{[10]}$.

The redox reactions and their pattern of reactivity have played a significant role in biochemical and atmospheric reactions. The work of R. A. Marcus [11] and Henry Taube ${ }^{[12]}$ in redox systems unequivocally demonstrated the transport of electron from reductant to oxidant. This discovery certainly added many important features in the syntheses of coordination complexes and organometallics. It is such a subject which has manifestations in almost all walks of life. As a result, oxidation-reduction reaction needs at least all two reactants, one capable of gaining electrons (oxidant) and the other capable of losing electrons (reductant), i.e., a reducing agent (reductant) by losing electrons, gets oxidised and an oxidising agent (oxidant), by gaining the electrons, gets reduced.

The reaction thus consists of transfer of electron from a reducing agent to an oxidising agent, so that there cannot be oxidation without concomitant, reduction. Such cases where oxidation and reduction are involved are commonly termed as redox reactions; and such a redox system involves a redox potential. It follows automatically, that any oxidation reduction reaction must involve two redox couples that differ in their affinity for electrons. This affinity of atoms for electrons is conferred to them by their particular atomic structure and it is expressed in terms of reduction potential or redox potential. Reduction potential of a redox couple is its tendency to get reduced from one oxidation state to another oxidation state. Redox reactions are also defined as involving changes in oxidation states or oxidation numbers. In a redox reaction, the oxidation number of the oxidant decreases and that of the reductant increases. The transfer of electrons is a book keeping device for effecting the changes states and for balancing the equations.

Particularly in aqueous solutions, it is usually possible to imagine atom or group transfer, rather than electron transfer, as occurring in a redox reaction. For example, iron (II) ion may act as a reducing agent by transferring a hydrogen atom from its hydration shell to a substrate.

$$
\mathrm{Fe}\left(\mathrm{H}_{2} \mathrm{O}\right)_{6}{ }^{2+}+\mathrm{R} \text {. ------------> } \mathrm{Fe}\left(\mathrm{H}_{2} \mathrm{O}\right)_{5} \mathrm{OH}^{2+}+\mathrm{RH}
$$

Iron (III) ion may act as an oxidising agent by transferring hydroxyl radical to a substrate:

$$
\mathrm{Fe}\left(\mathrm{H}_{2} \mathrm{O}\right)_{6}{ }^{3+}+\mathrm{R} \text {. ------------> } \mathrm{Fe}\left(\mathrm{H}_{2} \mathrm{O}\right)_{5}{ }^{2+}+\mathrm{H}^{+}+\mathrm{ROH}
$$

In general, transfer of a positive group or atom is equivalent to the transfer of electron and transfer of a negative group or atoms is equivalent to the taking up of electrons. The problem, then, in studying the mechanism of an Oxidationreduction reaction, is to find out whether atom transfer or electron transfer occurs, which atoms are transferred, and what intermediates, stable or unstable species are formed. A complete study would include a detailed picture of the transition state for all steps involved. Not only the composition but also the geometry of the transition is desired.

\section{OXIDATION-REDUCTION IN INORGANIC REACTIONS}

Two general classes of transition states emerge for redox reactions involving metal complexes, the so called outersphere and inner-sphere ${ }^{\text {tyre }}{ }^{[13]}$. In the first of these, the inner coordination shells of both the metal ions are intact in the transition state. In the second case, the two metal ions are connected through a bridging ligand common to both the coordination shells. From Franck-Condon Principle, it follows that before electron transfer between two ions is possible, the energy of the electron must be the same in the two sites. There must also be sufficient orbital overlap between the two sites to provide for a reasonable probability of a transfer.

In the case of reaction of outer-sphere type, the electron must wait for appropriate fluctuation of the ions and their coordination spheres, without in any way being able to influence the changes required in the site to which it will be transferred. For reactions of inner-sphere type, an activated complex of the type $L_{X}-M^{+n+1}-X-M^{n} W_{X}$ may be formed, 


\section{DOI: 10.17148/IARJSET.2021.81208}

where $\mathrm{L}, \mathrm{X}$ and $\mathrm{W}$ are ligands. In arriving at a configuration having $\mathrm{X}$ as a bridging group either $\mathrm{M}^{\mathrm{n}+1}$ or $\mathrm{M}^{+\mathrm{n}}$ (or both) has undergone substitution in the coordination sphere. Delocalisation of an electron over two sites will lower the energy Deeded for the formation of the activated complex and the electron will be able to affect the energy required to produce a fluctuation at the site to which it is going to be transferred.

Presumably the reaction is consummated by the fluctuation which causes the separation of $\mathrm{M}^{+\mathrm{n}+1}$ and $\mathrm{M}^{+\mathrm{n}}$ and may well require other changes in the coordination sphere as well. A feature of the bridge activated complex is that the bridging group may move from the oxidising agent to the reducing agent.

The most conclusive evidence for the mechanism comes from isolation of the products, which is possible only if the appropriate solvolysis reaction occur slowly. However, the reaction of $\mathrm{Cr}$ (II) and some of the reactions of V(II) and $\mathrm{Fe}(\mathrm{II})$ are convincingly characterised as following the inner-sphere mechanism. In the latter case, the immediate V(III)$\mathrm{X}$ or $\mathrm{Fe}(\mathrm{III})-\mathrm{X}$ products have often been detected spectrophotometrically, prior to their dissociation [14-16]. Therefore, probably the inner-sphere mechanism is the most favourable provided, (a) a suitable ligand is available in the coordination sphere of the oxidising complex and (b) substitution of a water molecule in the reducing agent occurs sufficiently rapidly to permit the transition state $\mathrm{M}-\mathrm{X}-\mathrm{M}$ to from rapidly ${ }^{[17]}$, The most common instances of outersphere mechanism are found when nature of the coordination sphere of one reductant of other contains ligands unsuited for bridging or when exchange occurs too slowly to permit bridge formation. Among such reactions ${ }^{[17]}$ are $\mathrm{Co}\left(\mathrm{NH}_{3}\right)_{6}{ }^{3+}$ Oxidations and $\mathrm{Cr}(\text { bipy })_{3}{ }^{2+}$ reductions; certain reactions of $\mathrm{V}\left(\mathrm{H}_{2} \mathrm{O}\right)_{6}{ }^{2+}$ which undergo substitution more slowly than most divalent ions, electron exchange of $\mathrm{Fe}\left(\mathrm{C}_{5} \mathrm{H}_{5}\right)^{2}$ and $\mathrm{Fe}\left(\mathrm{C}_{5} \mathrm{H}_{5}\right)^{2+}$; and reactions such as electron exchange of $\mathrm{Fe}(\mathrm{CN})_{6}{ }^{3-}$ and $\mathrm{Fe}(\mathrm{CN})_{6}{ }^{4-}$

\section{OXIDATION-REDUCTION IN ORGANIC REACTIONS}

The oxidation-reduction concepts, however, are not so clearly applicable in organic chemistry, for when carbon compounds are oxidised their component atoms are very seldom deprived of their surrounding complete electron shells. Covalent bond fission is an essential feature of organic reactions and it can be effected by two different pathways [18], viz., "Homolytic reactions" in which electron pairs are symmetrically disrupted and "Heterolytic reactions" in which electron pairs are transferred from one molecule to another as an undivided entity. Electron removal by these two pathways have clearly distinguishable characteristics.

In homolytic oxidations electrons are removed singly from organic molecules by active atoms such as chlorine, or by active free radicals. Though, molecules containing unshared electrons can be oxidised in this way, homolytic oxidations usually involve the removal from an organic molecules of one electron together with a hydrogen atom e.g.,

$$
\mathrm{R}_{3} \mathrm{C}-\mathrm{H}+\mathrm{Cl} \text {---------> } \mathrm{R}_{3} \mathrm{C} .+\mathrm{HCI}
$$

The initial organic product necessarily has unpaired electron and so must perforce undergo a reaction of similar type e.g.,

$$
\mathrm{R}_{3} \mathrm{C} .+\mathrm{CI}-\mathrm{Cl} \text {---------> } \mathrm{R}_{3} \mathrm{C}-\mathrm{Cl}+\mathrm{CI} \text {. }
$$

or must combine with another free radical before stable entities alone result. Thus, chain reactions, dimerisations or disproportionations e.g.,

$2 \mathrm{C}_{2} \mathrm{H}_{5}$. --------> $\mathrm{C}_{2} \mathrm{H}_{6}+\mathrm{C}_{2} \mathrm{H}_{4}$ are typical homolytic reactions.

All homolytic electron transfer reactions, such as above require very much less activation energy than needed for direct breakage of a covalence. Hence, homolytic oxidations, when once started, proceed very rapidly indeed. The traces of free radicals required for the initiation of homolytic oxidation may be formed by thermal dissociation of molecules which have weak covalences, by disruptions of molecules by exposure to radiant energy, high energy particles ( $\alpha$ particles) or electrons ( $\beta$-articles) or by single electron transfer, from ions of transition elements which can have incomplete inner electron shells (d--) shells consequently oxidations which are demonstrably prone to catalysis in these ways are homolytic in type.

Heterolytic oxidations involve the attack on organic compounds of electrophilic reagents which can, by a single process gain control of a further electron pair. Heterolytic oxidants therefore attack the exposed electron pairs of atom such as oxygen, nitrogen or sulphur or the loosely held n-electrons of olefins, rather than buried electron pairs of C- $\mathrm{H}, \mathrm{O}-\mathrm{H}$ or $\mathrm{N}-\mathrm{H}$ bonds. Again, Heterolytic reactions yield stable molecular or ionic products in one or at most two consecutive stages and very seldom lead to chain reactions. On the other hand, the usually require higher activation energy than homolytic reactions and so tend to be slower processes. Use of catalyst lowers the activation energy in such case. When heterolytic reactions are subjected to catalyst, the mechanism of catalyst is largely different from the catalysis involved in the case of homolytic reactions. 
Oxidations-Reduction reaction may involve one or more electron transfer. Depending upon the number of electrons transferred between oxidant and reductant, the reaction may proceed in one or more steps. Transition metals such as iron and cobalt and several others usually exhibit stable oxidation states differing by one electron and react with each other through one equivalent steps. However, the stable oxidation states in post transition elements such as arsenic, antimony etc., differ by two electrons. 1Thus, on the basis of their pattern of reactivity, the reactions of these elements are classified into two main categories ${ }^{[\mathbf{1 2}, \mathbf{1 9 - 2 4}]}$,

\section{COMPLEMENTARY REACTIONS AND NON-COMPLEMENTARY REACTIONS.}

Complementary reactions are those reactions in which oxidant and reductant both undergo two-equivalent changes or one equivalent change. These reactions generally obey a bimolecular rate equation and and the electron transfer can take place in a single step or in two step of one electron each. In TI(I) ----- Tl(III) exchange reactions, electrons are transferred in a single step as the formation of intermediate, $\mathrm{Tl}(\mathrm{II})$ is not detected. On the other hand the oxidations of $\mathrm{As}(\mathrm{III}){ }^{[25]}$ and $\mathrm{Sb}(\mathrm{III})^{[26]}$ by $\mathrm{Tl}(\mathrm{III})$ are other reactions where no evidences for the formation of $\mathrm{Tl}$ (II) has been obtained. The evidence obtained for the formation of As(IV) in pulse radiolytic studies indirectly supports one equivalent steps in As(III) oxidations. However, such an evidence in the reaction of As(III)-Tl(III) has not been observed. It is assumed that As(IV) is formed in the reaction (i) then it is very much likely that the two intermediates $\mathrm{Tl}(\mathrm{II})$ and As(IV) react with each other before they can diffuse out of the solvent cage which they are found.

$$
\mathrm{As}(\mathrm{III})+\mathrm{Tl}(\mathrm{III}) \text {---------> Tl(II) + As(IV) }
$$

A large number of complementary reactions have been explained by assuming the formation of bridging activated complex between oxidant and reductant further facile transfer of electron through the bridging ligand.

\section{NON-COMPLEMENTARY REACTIONS}

Non-complementary reactions are those in which oxidant and reductant undergo unequal equivalent changes such as one-equivalent oxidant interacts with two equivalent reductant and two-equivalent oxidant interacts with oneequivalent reductant. There are a number of possibilities of electron transfer in non-complementary reactions and these are related to the nature of both oxidant and reductant.

\section{MULTI EQUIVALENT REACTIONS}

Oxidising agents such as $\mathrm{Cr}(\mathrm{VI})$ and $\mathrm{Mn}(\mathrm{VI})$ undergo net changes of 3 and 5 units in oxidation number respectively during their reactions in acidic solution. For the most part, these reaction occur by one or two electron steps, with the necessary intervention of unstable intermediate oxidation states of $\mathrm{Cr}$ or $\mathrm{Mn}$. The reactions of $\mathrm{Cr}(\mathrm{VI})$ with transition metal complexes generally proceed by sequential one-electron step ${ }^{[17]}$, but post transition metal ions and non-metallic compounds, two electron steps appear to be preferred.

Electron transfer reactions are found to be governed by two classical principles

(a) Michaelis principle of compulsory univalent oxidation steps ${ }^{[27]}$

(b) Shaffer's principle of equivalent change ${ }^{[28,29]}$

Michaelis hypothesis involves the principle that an oxidation-reduction reaction takes place in one or more successive single electron transfer steps. This principle evolved from a considerations of restricted field of redox reactions, of which the axidation of hydroquinones to quinines through semiquinone intermediate is typical and is now generally recognized as being without universal validity, Apart from the reactions involving metal ions, many two equivalent redox reactions are now known which proceed in one step through the transfer of hydride ion or an oxygen atom ${ }^{[30,31]}$.

$$
\text { e.g. } \quad \mathrm{NO}_{2}^{-}+\mathrm{OCl}^{-}---------->\mathrm{NO}_{3}{ }^{-}+\mathrm{Cl}^{-}
$$

The second principle ${ }^{[\mathbf{2 8 , 2 9 ]}}$ refers to the observation that non-complementary reactions are often slow compared with complementary one's. Examples are the slow reduction of Tl(III) by Fe(ll) or Ce(IV) by TL(I) as compared to the rapid reduction of $\mathrm{TI}(\mathrm{III})$ by $\mathrm{Sn}(\mathrm{II})$ and $\mathrm{Ce}(\mathrm{IV})$ by $\mathrm{Fe}(\mathrm{II})$.

One of the implications of the comparison on which the principle of equivalence change is based is that reactions between 2-equivalent oxidants and 2-equivalent reductants occur by a concerted 2-equivalent step. This may well be the case for reactions such as the Tl(I) --- Tl(III) exchange ${ }^{[32-34]}$. The observation expressed by Shaffer, for noncomplementary reactions, is based on the low probability of termolecular mechanism as one possibility or the formation of the unstable valence states as the other possibility ${ }^{[23]}$. Another expected feature of these reactions will be the frequent occurrence of catalysis since the normal paths will be slow. 
The formation of unstable Oxidation states during the course of non-complementary reactions has been now anticipated in a number of such reactions with sufficient proofs. For example, the reductions of TI(III) by Fe(II) ${ }^{[35-37]}$, V(III) or

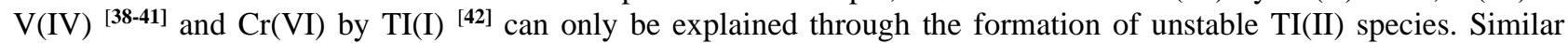
unstable oxidation states have been observed in other studies ${ }^{[40,41]}$. The interconversions between $\mathrm{Cr}(\mathrm{III})$ and $\mathrm{Cr}(\mathrm{VI})$ always appear to involve the unstable states $\mathrm{Cr}(\mathrm{IV})$ and $\mathrm{Cr}(\mathrm{V})$.

In a classic stady, King and Tong ${ }^{[43]}$ have worked out the details of the redox reactions between $\mathrm{Ce}(\mathrm{IV})$ and $\mathrm{Cr}$ (III) in aqueous sulphuric acid. The rate law was found to be as in equation (ii) which is very reasonably explained by the mechanism involving steps of equation (iia) to (iic).

$$
\text { Rate }=\mathrm{k}[\mathrm{Ce}(\mathrm{IV})]^{2}[\mathrm{Ce}(\mathrm{III})] /[\mathrm{Ce}(\mathrm{III})]
$$

The first step is a rapid equilibrium, and a second step, the inter conversion of $\mathrm{Cr}(\mathrm{IV})$ to $\mathrm{Cr}(\mathrm{V})$ is rate determining.

$$
\begin{array}{llll}
\mathrm{Ce}(\mathrm{IV})+\mathrm{Cr}(\mathrm{III}) \text {--------> } & \mathrm{Ce}(\mathrm{III})+\mathrm{Cr}(\mathrm{IV}) & \text { fast } & \text { (iia) } \\
\mathrm{Ce}(\mathrm{IV})+\mathrm{Cr}(\mathrm{IV}) \text {--------> } & \mathrm{Ce}(\mathrm{III})+\mathrm{Cr}(\mathrm{V}) & \text { slow } & \text { (iib) } \\
\mathrm{Ce}(\mathrm{IV})+\mathrm{Cr}(\mathrm{V}) \text {--------> } & \mathrm{Ce}(\mathrm{III})+\mathrm{Cr}(\mathrm{VI}) & \text { fast } & \text { (iic) }
\end{array}
$$

Excellent support comes from the study of related reactions such as the oxidation of vanadyl ion acid chromate ion [44] $\left(\mathrm{HCrO}_{4}^{-}\right)$and the analytical importance oxidation of ferrous ion by acid chromate ${ }^{[45]}$. It is significant that in the above example the change over from $\mathrm{Cr}(\mathrm{IV})$ to $\mathrm{Cr}(\mathrm{V})$ or vice versa, a change in coordination number from 6 to 4 occurs ${ }^{[43]}$. The stoichiometric examination of the reaction between acid chromate and $\mathrm{Fe}(\mathrm{II})$ are $\mathrm{VO}^{2+}$ in presence of iodide leads to the conclusion that the rapid oxidation of iodide ${ }^{[46]}$ is because of its reaction with $\mathrm{Cr}(\mathrm{V})$. A related phenomenon is seen in the oxidation of As(III) by peroxodisulphate ion. This slow reaction is accelerated or oxidation is induced by adding $\mathrm{Fe}$ (II) and the reaction is postulated to go by the formation of $\mathrm{As}(\mathrm{IV})$ from the reaction (iiia, iiib).

$$
\begin{aligned}
& \mathrm{Fe}(\mathrm{II})+\mathrm{S}_{2} \mathrm{O}_{8}{ }^{2-}------>\mathrm{Fe}(\mathrm{III})+\mathrm{SO}_{4}{ }^{2-}+\mathrm{SO}_{4}{ }^{-} \\
& \mathrm{As}(\mathrm{III})+\mathrm{SO}_{4}
\end{aligned}
$$

As mentioned earlier, another feature of these unstable oxidation states is the frequent occurrence of catalysis. A number of studies of the catalysis by platinum metals of oxidation reactions have been made ${ }^{[47]}$. The catalysis by $\mathrm{Ag}()$, $\mathrm{Cu}(1), \mathrm{Mn}(11)$ and $\mathrm{Cr}(\mathrm{III})$ in oxidation-reduction reactions so found to occur through formation of unstable oxidation states ${ }^{[48]}$.

\section{ACTIVE SPECIES}

If a particular substance (oxidant, reductant or catalyst) is capable of existence in several forms in aqueous solution, all the species existing may not be active. Those species which are involved in a slow step will influence the reaction. The reaction conditions will detemine the nature of the active species.

Moore and Anderson ${ }^{[49]}$ have reported that three or four species of $\mathrm{Ce}(\mathrm{IV})$ exist in sulphuric acid depending on its strength and the main active species in dilute solutions is $\mathrm{Ce}\left(\mathrm{SO}_{4}\right)^{2+}$. Hardwick and Robertson ${ }^{[50]}$ have give the following equilibria amongst various species of $\mathrm{Ce}(\mathrm{IV})$ in sulphuric acid solutions. The concentration of $\mathrm{H}^{+}$, $\mathrm{HSO}_{4}^{-}$, and $\mathrm{SO}_{4}{ }^{2-}$ would determine the nature of the active species.

$$
\begin{aligned}
& \mathrm{Ce}^{4+}+\mathrm{HSO}_{4}{ }^{-}------------>\mathrm{CeSO}_{4}{ }^{2+}+\mathrm{H}^{+} \\
& \mathrm{CeSO}_{4}{ }^{2+}+\mathrm{HSO}_{4}{ }^{-}--------->\mathrm{Ce}\left(\mathrm{SO}_{4}\right)_{2}+\mathrm{H}^{+} \\
& \mathrm{Ce}\left(\mathrm{SO}_{4}\right)_{2}+\mathrm{HSO}^{-}---------->\mathrm{HCe}\left(\mathrm{SO}_{4}\right)_{3}{ }^{-}
\end{aligned}
$$

To formulate the reaction rate as a function of species concentration, therefore, requires a knowledge of the existence of such equilibria and generally speaking, the knowledge of determination of one or more equilibrium constants. The distinction between the species and laboratory concentrations is particularly critical in the cases of partially displaced equilibria, because the rate equations, if cast in the form of reaction rate as a function of laboratory concentration, quite often resemble the equations applicable to different mechanisms.

\section{EFFECT OF IONS ON THE RATE}

The rates of redox reactions of complex ions are highly sensitive to the presence of other ions in the solution. Usually, added anions have the greater influence on the reaction of two cations each other and added cations influence the rate of two anions with each other. Large effects of anions on the rate are usually attributed to the formation of bridged species if labilecomplexes are involved.

In the redox reaction between two cations, if the reducing agent is complexed first, it will be more stabilised in the oxidised form and hence the reaction is speeded up in the presence of anion. Also a negative ion should enable to positive ions to approach each other more easily. This will be more effective if the negative ion is between the cations in the transition state. 


\section{International Advanced Research Journal in Science, Engineering and Technology}

\section{Vol. 8, Issue 12, December 2021}

\section{DOI: $10.17148 /$ IARJSET.2021.81208}

If the oxidising agent is complexed first the anion may stabilise it and slow down its rate of reaction. For example, the rate of reactions of $\mathrm{Ce}$ (IV) Oxidations are reduced strongly by fornming sulphate complexes [51] in presence of sulphate. This shows, in agreement with the theory that the coulombic repulsions between reactants do not play a dominant role. The conclusions to be drawn are not that electrostatic factors do not exist, but that other factors are of greater importance. Some significant effects of chloride ions are particularly noticeable in redox reactions, The redox reactions in which the reductant is able to form complexes with chloride are Tl(I), $\mathrm{Pd}(\mathrm{II}), \mathrm{Sn}$ (II) and $\mathrm{Sb}(\mathrm{II})$.

\section{CATALYSIS}

Any substance, other than reactants which influence the rate of chemical reaction and itself remains unchanged chemically at the end, is called catalyst. The phenomenon of rate alteration is designated as catalysis. Catalysts influence the reactions by changing the reaction path. Such catalytic influences arise as consequences of lowering of the energy of activation.

Catalyst development and synthesis have become a wide spread research field because of the increasing global demand for better system in chemical industry. Today, the chemical industry has been blamed for producing environmentally hazardous substances, which cause acid rain, a reduction of stratospheric ozone levels and so on. Many industrial processes have become burden on the environment, and, therefore must be essentially replaced by more eco-friendly or compatible processes in addition to this disposing of by-products or converting them into environmentally non hazardous substances consume much energy. The successful exploitations of a material as a catalyst will give valueadded products with improved yields and also eliminate or minimize environmental pollutants.

In solution involving inorganic oxidations, the catalysts are 1ons having unstable oxidation states. This case is a particular example of homogeneous catalysis where the catalyst presents in the same fields as a part of reactants. Though, the mechanism of catalysis depends on the nature of the substrate, oxidant and other experimental conditions, it has been shown that metal ion acts as catalyst by one of the following paths ${ }^{[52[}$.

(a) The catalyst is first oxidised by the oxidant to its higher oxidation states which in a subsequent step oxidises the substrate.

(b) The catalyst forms a complex with oxidant, the complex then oxidises the substrate either in the rate determining or in a fast step.

(c) The catalyst itself first oxidises the substrate in a slow step and the reduced form of the catalyst is oxidised by the oxidant in a fats step

(d) The catalyst traps the radical produced as intermediates and oxidises them at faster rate.

Osmium (VIII) is case in point as it been utilised ${ }^{[18]}$ as catalyst for hexacyanoferrate(III) oxidation of organic and inorganic substrate. The catalysis is understood to be due to the intervention of intermediate oxidation states of osmium. The detailed picture of its catalytic action has been reviewed by Upadhaya et al ${ }^{[53]}$.

Often, very small quantities of catalysts like $\mathrm{Ru}(\mathrm{III})^{[54]}, \mathrm{Pd}(\mathrm{III}){ }^{[55]}, \mathrm{Cr}(\mathrm{III})^{[56]}, \mathrm{Ru}(\mathrm{III}){ }^{[57]}, \mathrm{V}(\mathrm{V}){ }^{[58]}$ etc, are causes appreciable rates accelerations of particular reactions ${ }^{[47,48]}$. The increase in rate depends o the catalyst concentrations and hence, a kinetic-catalytic method of analysis of the catalytic species becomes available. Thus, a method of analysis down to the ppm level is possible in several cases ${ }^{[59]}$

\section{CONCLUSION}

The reaction between periodate and Guanidine hydrochloride in alkaline medium has a stoichiometry of 2:1 with first order dependence each on [Perioate] and $[\mathrm{Ru}(\mathrm{III})]$ and fractional order in $\left[\mathrm{OH}^{-}\right]$, while a zero order dependence on [Guanidine hydrochloride). No effect of added products, ionic strength dielectric constant has been observed. Investigation at different temperatures allowed the determination of the activation parameters with respect to slow step of the proposed mechanism.

Further a minute quantity $\left(10^{-6} \mathrm{~mol} \mathrm{dm}^{-3}\right)$ of Ruthenium(III) is sufficient to catalyse the reaction. The active species of Ruthenium(III) is found to be $\left[\mathrm{Ru}\left(\mathrm{H}_{2} \mathrm{O}\right)_{6}\right]^{3+}$. The overall mechanistic sequence described here is constituent with product studies, mechanistic studies and kinetic studies.

Further in presence of Ruthenium(III) catalyst the reaction seems to occur considerably fast that can be seen by comparing the rate constants of uncatalysed and catalysed reaction. Thus receiving the attention to study the activity of $\left[\mathrm{Ru}\left(\mathrm{H}_{2} \mathrm{O}\right)_{6}\right]^{3+}$, in such media. 


\title{
International Advanced Research Journal in Science, Engineering and Technology
}

\author{
Vol. 8, Issue 12, December 2021
}

\section{DOI: $10.17148 /$ IARJSET.2021.81208}

\section{REFERENCES}

1. F. A. Cotton and G. Wilkinson. "Advanced Inorganic Chemistry", A comprehensive Text, 5 ed., Wiley Interscience, (1968).

2. G. A. Hiremath, P. L. Timmanagoudar, R. B. Chougale and S.T. Nandibewoor, J. Indian chem.., Soc., 75, 363(1998); G. A. Hiremath, P. L. Timmanagoudar and S. T. Nandibewoor, J. phys.Org.chem.11. 31(1998); G. A. Hiremath, P. L. Timmanagoudar and S. T. Nandibewoor, J. Indian Chem. Soc., 76.250 (1999). M. A. Angadi, A. L. Harihar Oxidn. Commun, 31 No.1, 188 (2008)

3. F. V. Ranturjk L. Matt, Kieboom and p. G. Antomous, Carbohydr. Res., 226, 253 (1992);

L. Kamble and S. T. Nandibewoor, J. phys. Org. chem. 11. 171(1998); G. F. Smith and H. Diehl, Talanta, 4, 185 (1960) S. T. Nandibewoor and G. H. Hugar, Oxidn. Commun., 2, 222 (1999).

4. C. P. Kathari, A. L. Harihar. Indian J. Chem, Vol 40A, July 2001. (2001) pp. 747.

5. Rajani. S. Sunagar, A. L. Harihar J. Indian Chem. Soc, Vol 85, Oct, (2008). Pp. 996

6. G. H. Hugar and S. T. Nandibewoor, Transition Met. Chem., 1994, 19, 215; M. C. Agrawal and S. K. Upadhya, J. Sci. Ind. Res., 1983 , $42,508$.

7. Suma Kaladagi and A. L. Harihar Oxidn, Commun., Communicated (2009).

8. G. P. Panigrahi and P. K. Misro, J. Indian Chem. Soc., 154A, 1066 (1977).

9. Sir. G. Wilkinson,

"Comprehensive Coordination Chemistry", Vol 1, Pergamon Press, 1987, p.332

10. R. A. Sheldon and J. K. Kochi "Metal Catalysed Oxidation of Organic Compounds", Academic Press, New York, 1981

11. R. A. Marcus. J. Chem. Phys, 1956, 24, 966; Dive Faraday Soc., 1960,29, 21; J. Phys. Chem., 1963,67, 853, 2889; Ann Rev. Phys. Chem., 1964, 15, 155 Electrochim. Acta. 1968, 13,995; Chemische Elimetarprozesse, S. Pringer Berlin, 1968, p.348

12. H. Taube. "Electron Transfer Reactions of metal Complexes in Solution", Academic Press, New York, 1967.

13. H. Taube. "Advances in Inorganic Chemistry and Radiochemistry", Academic Press, New York, Vol. 1, 1959, p.1; D. Banerjee "Coordination Chemistry", McGraw-Hill, London, 1993, p. 408;

14. H. J. Price and H. Taube. Inorg. Chem., 1968, 7, 1

15. J. H. Espenson. J. Am. Chem. Soc., 1967, 89, 1276

16. A. Haim and N. Sutin. J. Am. Chem. Soc., 1966, 88, 5343

17. J. H. Espenson. "Homogeneous Inorganic Reactions", in "Techniques of Chemistry", Vol. VI, 3 edn., edited by E. S. Lewis, Wiley-Interscience, New York, 1973, pp.(a)596(b)598(c)599

18. W. A. Waters. "Mechanism of Oxidation of Organic Compounds". Methuen and Co. Ltd., London, 1964 , p.35

19. N. Sutin, F. Basolo and R. G. Pearson. "The Kinetics of Inorganic Reactions in Solution" Ann Rev. Phys. Chem., 1966, 17, 119

20. A. G Sykes. "Kinetics of Inorganic Reactions" Pergamom Press Ltd., London 1966

21. D. Benson. "Mechanism of Inorganic Reactions in Solution" McGraw-Hill, London, 1968

22. J. Halpern. "Mechanism of Electron Transfer and Related Processes in Solution", in Quart. Rev., 1961, 15, 207

23. F. Basolo and R. G Pearson. "Mechanism of Inorganic Reactions", John Wiley and Sons., Inc., $2^{\text {nd }}$ edn., New York, 1967, pp474-489

24. N. Sharma, R. Varadrajan, S. K. Mishra and P. D. Sharma. Chemistry Education. 1988, 8, 38

25. P. D. Sharma and Y. K. Gupta. J. Chem. Soc. Dalton Trans., 1972, 52

26. P. D. Sharma and Y. K. Gupta. J. Chem. Soc. Dalton Trans., 1973, 789

27. L. Michaelis. Trans. Electrochem. Soc., 1937, 71, 107; Cold Spring Harbor Symp. Quant. Biol., 1939, 7

28. P. A. Shaffer. J Am Chom Six, 1933, 55, 2169

29. 3. Halpern. Can \&Chem, 1959, 37, 148

30. M. Anabar and H. Taube \&Am. Chem. Soc., 1958, 80, 1073

31. R. Stewart. Experimentia 1959, 15,401

32. R. J. Prestwood and A. C. Wahl J. Am. Chem. Soc., 1949, 79, 3137

33. G. Harbottle and R. W. Dodson. J. Am. Chem. Soc., 1951, 73, 2442

34. S. W. Gilks and G. Nord-Waind Diss. Faraday Soc., 1960, 29, 102

35. C. E. Johnson, Jr., J. Am. Chem. Soc. 1952, 74,059

36. K. J. Ashurst and W. C. E. Higginson 3 Am. Chem. Soc., 1953, 3044

37. S. A. Chimatadar and J. R. Raju J. Inorg. Nucl. Chem., 1981, 43, 1947

38. W. C. E. Higginson, D. R. Rosseinsky, J. B. Stead and G. Sykes, Diss. Faraday Soc., 1960, 29, 49,

39. S. A. Chimatadar, S. T. Nandibewoor and J. R. Raju Indian J. Chem., 1985, 24A, 1075

40. S. M. Tuwar, S. T. Nandibewoor and J. R. Raju Trans. Met. Chem., 1991, 16, 196

41. S. M. Tuwar, S. T. Nandibewoor and J. R. Raju Indian J. Chem., 1991, 30A, 158

42. G. S. Gokavi and J. R. Raju Polyhedral, 1987, 6, 1721

43. E. L. King and I. Y. Tong J. Am. Chem. Soc., 1960, 82, 3805

44. J. H. Espenson J. Am. Chem. Soc., 1964, 85, 5101

45. J. H. Espenson and E. L. King J. Am. Chem. Soc., 1963, 85, 3328

46. F. H. Westhmier Chem. Rev., 1949, 45, 419

47. U. S. Mehrotra and S. P. Mushran Can. J. Chem., 1970, 48, 1148; U. S. Mehrotra, M. C. Agrawal and S. P. Mushram J. Inorg. Nucl. Chem., 1970, 32, 2325; S. P. Mushram, M. C. Agrawal and H. C. Gupta Indian J. Chem., 1972, 10, 642 S. A. Chimatadar, S. T. Nandibewoor and J. R. Raju Indian J. Chem., 1987, 26A, 255; S. M. Pandey, J. Sharma, O. Prakash and S. P. Mushran Indian J. Chem., 1981, 20A, 1021

48. J. Halpern and J. G. Smith Can. J. Chem., 1956, 84, 1419; S. K. Mishra and Y. K. Gupta J. Inorg. Nucl. Chem., 1968, 30, 2991; S. A. Chimatadar, S. T. Nandibewoor, M. I. Sambrani And J. R. Raju, J. Chem. Soc. Dalton Trans., 1987, 573

49. R. L. Moore and R. C. Anderson J. Am. Chem. Soc., 1945, 67, 167

50. T. J. Harwick and E. Robertson Can. J. Chem., 1951, 29, 828

51. P. George and D. H. Irvine J. Chem. Soc., 1954, 587

52. P. Veersomaiah, K. Balreddy, B. Sethuram and T. Navaneeth Rao, Indian J. Chem., 1987, 26A, 462

53. S. K. Upadhaya and M. C. Agrawal J. Sci. Ind. Res., 1983, 42, 508

54. P. L. Timmanagoudar, G. A. Hiremath and S. T. Nandibewoor Indian J. Chem., 1996, 35A, 1084; S. T. Nandibewoor and G. H. Hugar Polish J. Chem., 1997, 71, 1572; D. L. Kamble and S. T. Nandibewoor J. Phys. Org. Chem., 1998, 11, 171; S. M. Desai, N. N. Halligudi and S. T. Nandibewoor Int. J. ChemKinet., 1999, 31, 583 M.R. Kembhavi, A. L. Harihar and S.T. Nandibewoor React Kinet. Catal. Letts., 1999, 1.67; M.R. Kembhavi, A. L. Harihar and S.T. Nandibewoor Oxidn, Commun, 2000, 2, 304; S. K. Mavalangi, A. L. Harihar and S.T. Nandibewoor 


\section{International Advanced Research Journal in Science, Engineering and Technology}

\section{Vol. 8, Issue 12, December 2021}

\section{DOI: $10.17148 /$ IARJSET.2021.81208}

Oxidn, Commun., 2000, 1, 142; A. L. Harihar, S. K. Mavalangi and S.T. Nandibewoor Oxidn, Commun., 2007, 1, 30; M.A. Angadi and A. L. Harihar Oxidn, Commun., 2008, 1, 188;

55. V. A. Morab and S. T. Nandibewoor Kinet. Catal. Letts., 1994, 1, 25; G. A. Hiremath, P. L. Timmanagoudar and S. T. Nandibewoor J. Phys. Org. Chem., 1998, 11, 31 N. N. Halligudi, S. M. Desai and S. T. Nandibewoor Indian J. Chem., 1999, 38A, 943

56. S. A. Chimatadar, S. T. Nandibewoor, M. I. Sambrani and J.R. Raju, J. Chem. Soc. Dalton Trans., 1987, 573; V. A. Morab, S. M. Tuwar and S. T. Nandibewoor 2. Fr. PhysikChemie. 1999, 141: G. S. Gokavi and J. R. Raju Oxidn, Commun., 1998, 11, 205; S. T. Nandibewoor and V. A. Morab J. Chem. Soc. Dalton Trans., 1995, 483

57. G. A. Hiremath, P. L. Timmanagoudar and S. T. Nandibewoor React. Kinet, Catal. Letts., 1998, 63, 403; D. L. Kamble and S. T. Nandibewoor J. Phys. Org. Chem., 1998, 11, 171; N. N. Halligudi, S. M. Desai and S.T. Nandibewoor Trans, Met. Chem., (2000) (In Press)

C.P. Kathari, A. L. Harihar and S.T. Nandibewoor Int. J. Chem, Kinet, 2001, 12, 278

58. D. L. Kamble and S. T. Nandibewoor Int. J. Chem. Kinet., 1996, 28 A, 673.

S. M. Tuwar, S. T. Nandibewoor and J. R. Raju Indian J. Chem., 1990, 29A, 825; S. T. Nandibewoor and V. A. Morab J. Chem. Soc. Dalton Trans., 1995, 483 P. L. Timmanagoudar, G. A. Hiremath, and S. T. Nandibewoor Indian J. Chem., 1996, 35A, 1084 